DOI: $10.17805 /$ trudy.2015.3.2

\title{
ПЕРСПЕКТИВЫ РАЗВИТИЯ РУССКОГО ЯЗЫКА И РУССКОЙ КУЛЬТУРЫ В СОВРЕМЕННЫХ УСЛОВИЯХ
}

\author{
Э. Ф. Макаревич, О. И. Карпухин \\ (Московский гуманитарный университет)
}

Аннотация: В статье анализируется проблема языка как фактора национальной безопасности. Рассматриваются основные проблемы для развития русского языка и соответственно русской культуры - влияние глобализации, вестернизации.

Ключевые слова: русский язык, языковая экспансия, глобализация, русская культура, национальная безопасность.

\section{RUSSIAN LANGUAGE AND CULTURE: CURRENT DEVELOPMENT PROSPECTS}

\author{
E. F. Makarevich, O. I. Karpukhin \\ (Moscow University for the Humanities)
}

\begin{abstract}
The article looks at language as a factor of national security, with a special focus on the main issues of the development of Russian language, and consequently, of Russian culture, such as the impact of globalization and Westernization.

Keywords: Russian language, linguistic expansion, globalization, Russian culture, national security.
\end{abstract}

Язык - инструмент производства новых смыслов и образов, прямых и рефлексирующих. Но вспомним А. С. Пушкина: в языке должна быть «соразмерность» человеку, месту и времени. Если смыслы и образы будут адекватны пространству и времени, их запомнят. На это стал способен русский язык, созданный Пушкиным. Это был новый язык, свободный от клише, свободный в соединении и значении слов, а потому поэтическипублицистический, коммуникационный язык.

Б. М. Гаспаров предложил гипотезу лингвистического существования. Суть ее в том, что особенность языка говорящего можно понять и почувствовать, если сосредоточиться на бесконечном и нерасчлененном потоке 
языковых действий, выраженных мыслями, представлениями, воспоминаниями, переживаниями, т. е. совокупностью образов, включающих рациональное и эмоциональное. Чем богаче образы переживания (а богатство это - явное производное от литературы), тем ярче язык, который их передает. Тогда поток языковых действий рождает своеобразный артефакт, который проявляется в реакции контрпозиционной стороны. Но реакция эта невозможна без духовного начала как у стороны, рождающей артефакт, так и у стороны, воспринимающей его. Без духовного начала, которое идет от литературы, без взаимодействующих сторон невозможно создание новых смыслов. Богатство мысли, представлений, воспоминаний, переживаний - условие появления новых образов, порождающих новые смыслы.

Еще в 1940 г. известный языковед Л. В. Щерба ввел в лингвистику понятие «тезаурус», но развить его в коммуникативной практике не получилось. А тезаурус давал новые возможности для коммуникаций, потому что он подразумевал наличие открытой и подвижной системы значений, хранящихся в памяти индивида и организованных по принципу: от общего к частному внутри определенной сферы употребления. Во многом тезаурус формировался коммуникативным окружением индивида, вбирающим в себя особенности того социально-культурного контекста, в котором протекает знаковое общение с другими людьми. Зародившаяся в СССР в 19401950-е годы психолингвистика (а языковое сознание оттуда) не обогатила коммуникативные процессы из-за «подозрительного» отношения к ней.

А на Западе набирали силу и психолингвистика (Н. Хомский) и социолингвистика (Х. Карри), которые исследовали отражение различных социальных и социально-психологических явлений и процессов, роль языка в жизни и развитии общества. И когда социология заявила о возможности социального конструирования реальности (П. Бергер, Т. Лукман), лингвисты взялись за изучение роли языка в этом процессе. Они доказали способность языка к созданию грандиозных систем символических представлений, которые возвышаются над реальностью повседневной жизни подобно явлениям иного мира (Бергер, Лукман, 1995: 70). По сути, эти исследования вывели массовые коммуникации на новый, глобальный уровень.

Но язык - такая субстанция, которая живет не только сознанием, но и чувствами. Ускорение совершенствования «чувственной» стороны языка, развиваемой литературой, публицистикой, так же возможно, как и ускорение процессов интеллектуализации языка, развиваемой наукой. Когда поэзия смыкается с рациональным знанием, это, несомненно, открывает новые возможности для массовых коммуникаций.

Литературный язык - «высший» язык. И чем «мощнее» культура, которую выражает этот язык, тем «мощнее» сам язык, тем больше у него 
возможностей быть средством создания ярких, запоминающихся образов, стать языком межнационального общения. Русский язык - в числе мировых языков. Выдвижение языка на роль мирового определяется общечеловеческой значимостью культуры, созданной на этом языке.

О силе языка зависимого от культуры говорил А. П. Чехов: «Чем выше культура, тем богаче язык. Количество слов и их сочетаний находится в прямой зависимости от суммы впечатлений и представлений (читай - «образов». - Э. М., О. К.); без последних не может быть ни понятий, ни определений, а стало быть, и поводов к обогащению языка» (Чехов, 1977: 114).

Язык лучше всего передает душу, психологию народа. И когда говорят о русском народе, о его стремлении к извечной справедливости, о широте русской души, то подтверждение этому находят в языке, который все это выражает.

Но развивается ли этот язык сегодня? Темпы словарного обогащения русского языка в последние десятилетия сильно замедлились. Новые жизненные явления, процессы не всегда адекватно отражаются в языке. А язык «отставший» или вяло используемый теряет силу гуманитарного сопротивления. Пока снижение темпов обогащения словарного запаса русский язык восполняет своей гибкостью и выразительностью, что идет от Пушкина и других великих русских писателей. Обладающий выразительной интонацией, русский язык словно создан для массовых коммуникаций. В немалой степени именно интонационная особенность русского языка позволяет развивать тезаурус его, как множество смыслоразличительных элементов - словосочетаний, смысловых отношений.

Сила языка - это завоеванное массовыми коммуникациями пространство влияния на людей, это языковые формы сопротивления культурной экспансии. Внутри страны локальные битвы за русский язык происходят в основном в сфере гуманитарного образования. Но гораздо более серьезные сражения за язык идут в ряде бывших советских республик: отлучение их от сотрудничества с Россией начинается с вытеснения русского языка с их территорий, из всех сфер жизни.

По данным Центра демографии и экологии человека РАН, из 10-12 ведущих мировых языков только русский язык на протяжении последних десятилетий утрачивает свои позиции в мире. По прогнозам, к 2025 г. владеть русским языком будет не более 152 млн человек. Особенно заметна эта тенденция в странах СНГ (кроме РФ) и Балтии. Если за 15 лет количество не знающих русский язык в этих странах выросло от нуля до 38 млн человек (по официальным данным), то еще через 10 лет оно увеличится почти до 80 млн человек. В странах Восточной Европы в начале XXI в. русский язык знало около 20 млн человек, но предполагается, что в ближайшее время таковых станет вдвое меньше (Арефьев, 2006: Электр. ресурс). 
Сокращение сферы распространения русского языка в мире - это и сокращение российского влияния, как культурного, так и политического, это падение сопротивляемости глобальной культурной экспансии. В определенном смысле это удар и по российскому экономическому влиянию, поскольку наличие в той или иной стране русскоговорящих предпринимателей и финансистов весьма способствует развитию деловых и торговых отношений.

«Сопротивленческий» опыт имеется у стран Западной Европы. Это, прежде всего, образование лингвистических сообществ, в перспективе перерастающих в политические организации. Лидер гуманитарного сопротивления - Франция. Именно она стала инициатором в деле защиты родного языка. Вот что гласит первая статья Закона об использовании французского языка: «Являющийся государственным языком республики в соответствии с Конституцией, французский язык представляет собой основной элемент исторического лица и наследия Франции. Он служит средством образования, работы, обменов и услуг в государстве. Он является основной связью между государствами, составляющими сообщество франкоговорящих государств».

Еще на заре глобализации Франция инициировала франкофонное движение, сделав ставку на французский язык и культуру, объединив страны, пользующиеся французским языком, объединив людей, говорящих по-французски, использующих его как второй язык, язык культуры или изучающих его. В 70-е годы XX века это движение оформилось в Международную организацию Франкофония (МОФ). Это первое в мире объединение государств, ассоциаций и т. д. на лингвистической основе, ныне переросшее в политическую организацию на основе французского языка - общего для участвующих стран. Эта группа государств стала центром «франкофонной кристаллизации», выражающим идею гуманитарного сопротивления и экспансии. Страны Франкофонии придерживаются принципа, что между людьми, говорящими на одном языке, должны существовать особые связи. Франкофония - это не только совокупность людей и стран, говорящих на французском языке, это государственные и частные организации, это духовное партнерство, питаемое чувством принадлежности к одной духовной общности - французскому языку, французской культуре и воплощаемым ими ценностям, это использование достижений культуры и цивилизаций друг друга. Франция - лидер и главный спонсор Франкофонии - делает основной акцент на духовную составляющую объединившихся стран. В рамках МОФ разработана конституция франкофонного сообщества, учреждена конференция министров национального образования и культуры, действует Агентство по культурному и техническому сотрудничеству. 
Сегодня Франкофония объединяет более 70 стран, ассоциаций, университетов и т. п. МОФ сильна своей культурной составляющей. Ее основные лозунги: противостояние стандартам глобализации, сохранение национального достояния народов, развитие культурного и лингвистического разнообразия, диалог культур. Франция сумела мобилизовать лингвистический ресурс для формирования дружественного политического, экономического и культурного пространства. Языковая политика Франции в большей части подчинена интересам ее внешней политики (Пономаренко, Лаврова, 2005). Сложился механизм формирования лидеров «франкоговорящих» стран, которые являются приверженцами одновременно двух культур: своей национальной и французской.

Франция создала глобальную телесеть, которая может конкурировать с оккупировавшими информационное пространство британскими и американскими телеканалами. С 2006 г. во Франции работает круглосуточная служба новостей France 24. С помощью спутников и кабельных сетей France 24пришла к 75 миллионам зрителей в Европе, Африке и на Ближнем Востоке. Этот телеканал выдвигает Францию на передовой край всемирной битвы идей, бросая вызов таким медиагигантам, как BBC, CNN и «Аль-Джазира». Как говорят создатели этой телесети, она «будет отражать национальные ценности, любовь к спорам, дискуссиям и противоречивым идеям» (Сэмюэль, 2006).

Опыт Франции в сопротивлении культурной глобализации соответствующим образом интерпретировал для себя Китай. В 2004 г. китайское правительство одобрило программу «Chinese Language Bridge Program», которая направлена на пропаганду и распространение китайского языка в мире, прежде всего в США, Великобритании, Германии, Японии и Корее. Только за три года экзамен по китайскому языку сдали более 1,2 миллиона иностранцев. Во многих странах в качестве базы для культурных и научных обменов создаются «Институты Конфуция». Политика китайского руководства ориентирована на распространение языка в наиболее развитых государствах или в стратегически важных и ресурсно богатых развивающихся странах, которые представляют для Пекина наибольший политический интерес (Русский как иностранный, 2006: Электр. ресурс).

Русский язык тоже вынужден противостоять англоязычной экспансии. Возможная стратегия сопротивления та, которая подразумевает экспансию не столько русского языка как такового, сколько русской науки и культуры. Россия - одна из немногих стран мира, способная на своем языке вести научные изыскания, создавать теории и вносить вклад в мировое знание. Поэтому миссия России - развивать науки, продвигать их достижения, быть «производителем» научных трудов, учебников, справочников и энциклопедий по разным отраслям знаний. 
Мировая экономика, бизнес, промышленность, наука, дипломатия в подавляющей части используют английский язык. Русский язык потенциально предпочтителен как язык гуманитарного и нравственного общения, духовного самопознания и убеждения. В глобальном сообществе русский язык может стать языком диалога. Диалоговый потенциал русского языка, определяющий силу гуманитарного сопротивления - в его связи с русской литературой. Оторвать русский язык от великой русской литературы, - значит помешать формированию культурных кодов, сделать сознание и чувства молодого поколения особо податливыми для экспансии чужих смыслов и образов, значит отучить выражать свои мысли на литературном языке.

Советский Союз в Великой отечественной войне разгромил гитлеровскую Германию в том числе и благодаря духу народа. Дух народа воспитывался великой культурой. После войны в победившей стране был провозглашен культ российской истории и русской культуры: литературы, театра, кино, музыки. Укреплению этого культа способствовала начавшаяся «холодная» война. В речи У. Черчилля, произнесенной им в марте 1946 г., была изложена идеология этой войны: братская ассоциация народов, говорящих на английском языке, должна на основе военной силы найти взаимопонимание с Россией. Сталин, отвечая на это заявление в интервью газете «Правда», сделал особый акцент на «языковом» противостоянии: «По сути дела, господин Черчилль и его друзья в Англии и США предъявляют нациям, не говорящим на английском языке, нечто вроде ультиматума: признайте наше господство добровольно - и тогда все будет в порядке, в противном случае неизбежна война». Тогда, в начавшейся «холодной» войне с Западом, российская культура, особенно русская классическая и советская литература, были самым крепким бастионом гуманитарного сопротивления. Откуда такая крепость?

Особенность русской литературы в единении двух стилей - реализма как правдивого, неприкрашенного отображения жизни, и романтизма, но не пассивного, примиряющего человека с действительностью, а активного, укрепляющего волю человека в жизненной борьбе (Горький, 1979: 287). Сплав романтизма и реализма - истинный источник сопротивленческого духа русской литературы, который заключен в ее кодах свободы, справедливости, реформаторства и революционности.

Большевистские руководители очень хорошо понимали силу литературного слова. После победы Октябрьской революции в России, решая задачи пропаганды, они все чаще обращались к произведениям Пушкина, Лермонтова, Гоголя, Тургенева, Достоевского, Толстого, Чехова с их верой в Россию, в народ. Гражданскую позицию этих гениев литературы определил П. Вяземский, назвав их «либеральными консерваторами». Боль- 
шевистская власть стремилась примирить опыт идейного и нравственного влияния «либеральных консерваторов» с опытом «консерваторов советских», и выстроить образование и пропаганду в соответствии с этим примирением.

Достоевского замалчивали из-за «Бесов», но, тем не менее, отмечали, что неприглядность таких героев-революционеров в романе взывает к борьбе с ними. В самом начале 1935 г. издательство «Academia» (где директором был опальный Л. Б. Каменев) выпустило очередное издание романа «Бесы». А уже через несколько дней в «Правде» партийный критик Д. Заславский выступил со статьей «Литературная гниль», основной пафос которой - зачем переизданы «Бесы»? В статье досталось и автору романа, написавшему «грязнейший пасквиль, направленный против революции», и издательству за публикацию произведения. Вмешался М. Горький, который сказал, что он против превращения легальной литературы в нелегальную, которая будет соблазнять молодежь своей запретностью. И «Бесы» из авангарда литературного перекочевали в политический.

А разве для Сталина - Зиновьев, Каменев и Бухарин не бесы? Правда, и он для них был бесом, но у него была власть. Вождь внимательно читал сочинения и дневники Достоевского, и он оценил силу писателя, припечатавшего словом «бесы», по его разумению, «оборотней революции». Вот такой писатель был нужен Сталину, такой, который вывернул бы нутро нынешних бесов. А то ведь как «литераторы» из НКВД и отдела пропаганды ЦК партии обозначили внутренних врагов - «английские, немецкие, японские шпионы». А где яркое писательское слово? Такое, которое сказал Пушкин после подавления бунта в Польше (и Николай I это оценил!):

Сбылось - и в день Бородина

Вновь наши вторглись знамена

В проломы падшей вновь Варшавы;

И Польша, как бегущий полк,

Во прах бросает стяг кровавый -

И бунт раздавленный умолк

(«Бородинская годовщина»)

Могут ли нынешние поэты так сказать о победах? Вероятно, Сталин задавал себе этот вопрос и, наверное, признавал, что у Пушкина надо учиться современным мастерам мобилизующего жанра.

\section{СПИСОК ЛИТЕРАТУРЫ}

Арефьев, А. (2006) Сколько людей говорят и будут говорить порусски? [Электронный ресурс] // Демоскоп. № 251-252. URL: http://www. demoscope.ru/weekly/2006/0251/tema05.php (дата обращения: 12.03.2015).

Бергер, П., Лукман, Т. (1995) Социальное конструирование реально- 
сти. М. : Медиум.

Горький, М. (1979) Собрание сочинений : в 16 т. М. : Правда. Т. 16.

Пономаренко, Л. В., Лаврова, Е. В. (2005) Франкофония. История, структура, тенденции современного развития. М. : Изд-во РУДН.

Русский как иностранный (2006) [Электронный ресурс] // Коммерсантъ. 17 августа. URL: http://www.kommersant.ru/doc/698211 (дата обращения: 12.03.2015).

Сэмюэль, Г. (2006) Франс Телевизор // Газета. 7 декабря.

Чехов, А. П. (1977) Письмо Меньшикову М. О., 12 октября 1892 г. Мелихово // Чехов А. П. Полное собрание сочинений и писем : в 30 т. Письма: в 12 т. / АН СССР. Ин-т мировой лит. им. А. М. Горького. М.: Наука. Т. 5. Письма, Март 1892-1894. С. 114-115.

Макаревич Эдуард Федорович - доктор социологических наук, профессор кафедры философии, культурологии и политологии Московского гуманитарного университета. Адрес: 111395, Россия, г. Москва, ул. Юности, д. 5. Тел.: +7 (499) 374-55-11. Эл. адрес: edward.makarevich@mail.ru

Карпухин Олег Иванович - доктор социологических наук, профессор кафедры философии, культурологии и политологии Московского гуманитарного университета, Заслуженный деятель науки РФ. Адрес: 111395, Россия, г. Москва, ул. Юности, д. 5. Тел.: +7 (499) 374-55-11.

Makarevich Eduard Fyodorovich, Doctor of Social Science, Professor, Department of Philosophy, Culturology and Politology, Moscow University for the Humanities. Postal address: 5 Yunosti St., Moscow, Russian Federation, 111395. Tel.: +7 (499) 374-55-11.E-mail: edward.makarevich@mail.ru

Karpukhin, Oleg Ivanovich, Doctor of Sociology, Professor, Department of of Philosophy, Culturology and Politology, Moscow University for the Humanities. Postal address: 5 Yunosti St., 111395 Moscow, Russian Federation. Tel.: +7 (499) 374-55-11. 